\title{
Meduloblastomul - aspecte clinice şi terapeutice
}

\author{
Cătălin Prăzaru', Georgeta Diaconu', Ana Ulinici', H. Abou Ainain', \\ Alexandra Stoicescu Prăzaru², Ioana Grigore ${ }^{1}$ \\ ${ }^{1}$ Secţia de Neurologie Pediatrică, Spitalul Clinic de Urgenţe pentru Copii „Sf. Maria“, Iaşi, România \\ ${ }^{2}$ Secţia de Radioterapie, Institutul Regional de Oncologie, Iaşi, România
}

\begin{abstract}
REZUMAT
Meduloblastomul este o tumoră neuroectodermică primitivă întâlnită frecvent la vârsta pediatrică, cu incidență maximă între 5 şi 10 ani. Tumora este localizată în general la nivelul vermisului sau ventriculului IV invadând emisferele cerebeloase. Tabloul clinic este dominat de semne de hipertensiune intracraniană şi ataxie cerebeloasă. Explorările neuroimagistice contribuie la o diagnosticare şi stadializare cât mai precisă a meduloblastomului. Tratamentul este complex cuprinzând rezecția chirurgicală a tumorii urmată de radio/chimioterapie. Prognosticul este în general rezervat, incidența sechelelor neurologice după tratament fiind crescută.
\end{abstract}

Cuvinte cheie: meduloblastom, copil

Meduloblastomul (MBL) este o tumoră primară embrionară a cerebelului, considerată cea mai frecventă tumoră malignă intracraniană la copil, care reprezintă aproximativ $25 \%$ din totalul neoplaziilor sistemului nervos central (SNC) înaintea vârstei de 15 ani (1). A fost descris pentru prima dată în 1925 de către Cusing şi Bailey ca fiind o tumoră cerebeloasă cu celule mici şi grad mare de malignitate (2). Ulterior, în 1983, Rorke, Becker şi Hinton au propus ca meduloblastomul să fie inclus, alături de toate tumorile intracraniene cu celule mici, în categoria tumorilor neuroectodermale primitive (3). În prezent, nu mai sunt considerate entități similare deoarece, spre deosebire de MBL, tumorile neuroectodermale primitive supratentoriale au un profil genetic distinct, sunt mai agresive şi de obicei răspund slab la terapia specifică. Din aceste considerente, în cea de-a patra ediție a clasificării tumorilor embrionare ale SNC, publicată de Organizația Mondială a Sănătății în 2007, MBL rămâne o categorie distinctă de celelalte tumori neuroectodermale primitive (3).

Localizat în general la nivelul vermisului sau ventriculului IV, invadează emisferele cerebeloase. Tumora manifestă o tendinţă marcată de extensie în vecinătate şi de diseminare în spatiile subarahnoidiene, în particular spre regiunea rahidiană (1).
Meduloblastomul este rar întâlnit la adult, 75\% dintre cazuri fiind diagnosticate la copii cu vârstă sub 16 ani (4). Datele din literatură raportează o preponderență masculină de 2:1 a acestei afecțiuni (5).

\section{ASPECTE HISTOPATOLOGICE}

Meduloblastomul îşi are originea în celulele embrionare aflate la începutul stadiului de dezvoltare, care şi-au oprit diferențierea şi care determină tipul histologic. În aproximativ 50\% dintre cazuri, la examenul microscopic sunt detectate pseudorozete perivasculare (pseudorozete Homer Wright) şi celule tumorale caracteristice înconjurate de o zonă fibrilară (6). Din punct de vedere histopatologic tumora poate avea mai multe aspecte. În 2004, Eberhart clasifică MBL în 3 tipuri histopatologice: clasic sau nediferențiat, anaplastic, desmoplastic sau nodular. În urma studiilor recente genomice şi moleculare s-a stabilit că MBL prezintă 4 variante moleculare distincte. Studiile au relevat că fiecare subgrup molecular prezintă caracteristici demografice şi clinice particulare $(7,8)$.

Meduloblastomul grup 1 este forma cel mai rar întâlnită, fiind diagnosticat la aproximativ $10 \%$ din copii (9). Poate să apară la orice vârstă, dar este mai rar sub 3 ani. Repartiţia pe sexe este egală. Tumora 
este în general localizată pe linia mediană şi ocupă ventriculul IV. Rata de metastazare şi riscul de recurență sunt scăzute, supraviețiirea la 5 ani a acestor pacienți fiind de $95 \%$ (10).

Meduloblastomul grup2 reprezintă aproximativ $30 \%$ din totalul MBL, fiind mai frecvent întâlnit la grupa de vârstă 0-3 ani şi la copiii > 16 ani. Riscul de metastazare este scăzut, dar pot să apară recidive locale. Prognosticul depinde de vârsta de debut, fiind bun la copilul mic şi mai scăzut la adolescenți, supraviețuirea la 5 ani fiind de $75 \%$ (9).

Meduloblastomul grup3 este diagnosticat la aproximativ $25 \%$ dintre cazuri, este mai frecvent la sexul masculin, apare în general la sugari şi copii, rar la adolescenți şi niciodată la vârsta adultă (11). Riscul de apariție a metastazelor este crescut, aproximativ $50 \%$ dintre pacienți prezintă metastaze (12). Prognosticul este scăzut, rata de supraviețuire la 5 ani variază între 45 şi $58 \%(11,13)$.

Meduloblastomul grup4 este forma cea mai frecventă, fiind diagnosticat la aproximativ 35\% din totalul MBL (9). Poate să apară la orice vârstă, fiind totuşi mai rar întâlnit la sugari. Acest subgrup este mai frecvent întâlnit la sexul masculin, repartiția pe sexe fiind de 3:1 (11). Riscul de apariție a metastazelor este crescut, aproximativ $35-40 \%$ dintre pacienți prezintă metastaze $(11,13)$. Supraviețuirea la 5 ani variază între 60 şi 80\% (14).

Kool (2012) consideră că sistemul de clasificare moleculară a MBL poate îmbunătăţi schemele terapeutice, fiind important pentru prognostic.

Tabloul clinic este variat şi depinde de vârstă, nivelul dezvoltării neuromotorii a copilului anterior debutului simpomatologiei, localizarea şi gradul de extindere a tumorii. Semnele precoce, nespecifice, precum iritabilitatea, scăderea aptitudinilor şcolare şi fatigabilitatea sunt în general ignorate de pacient sau de aparținători. Într-un studiu efectuat în 2012, Brasme şi colaboratorii (5) au demonstrat existența unei întârzieri medii între apariția primelor semne ale MBL şi diagnostic de aproximativ 65 de zile, întârziere care a fost semnificativ mai mare la copiii care prezentau simptome psihiatrice (randament şcolar scăzut, tulburări de comportament şi modificări ale dispoziţiei).

Deoarece MBL se dezvoltă în general aproape de ventriculul IV se poate extinde în cavitatea ventriculară blocând circulația normală a lichidului cefalorahidian cauzând hidrocefalie şi determinând apariția semnelor de hipertensiune intracraniană. Într-un studiu realizat de Muzumdar (2007) pe un lot de 154 de pacienți diagnosticați cu MBL, 96,5\% asociau hidrocefalie (15). De asemenea, Kombogiorgas (2008) a raportat prezența hidrocefaliei la toți cei 20 de bolnavi cu MLB urmăriţi (16). La copilul mare semnele clinice din cauza creşterii presiunii intracraniene sunt reprezentate de cefalee, vărsături, tulburări de vedere, iar la sugari de macrocranie, bombarea fontanelei anterioare, iritabilitate. La $10 \%$ dintre pacienți torticolisul poate fi primul simptom (15).

În evoluție apare alterarea stării generale cu mişcări dezordonate ale globilor oculari, ambliopie şi ataxie cerebeloasă. La aproximativ $10-35 \%$ din pacienți sunt prezente în momentul diagnosticului semne din cauza metastazelor spinale manifestate în general prin rahialgii şi deficite motorii (17).

\section{DIAGNOSTIC}

Examenul neurologic detaliat al pacientului asociat examenului oftalmologic reprezintă prima etapă în diagnostic.

Examenul oftalmologic (FO) poate evidenția edem papilar in $90 \%$ dintre cazuri (18).
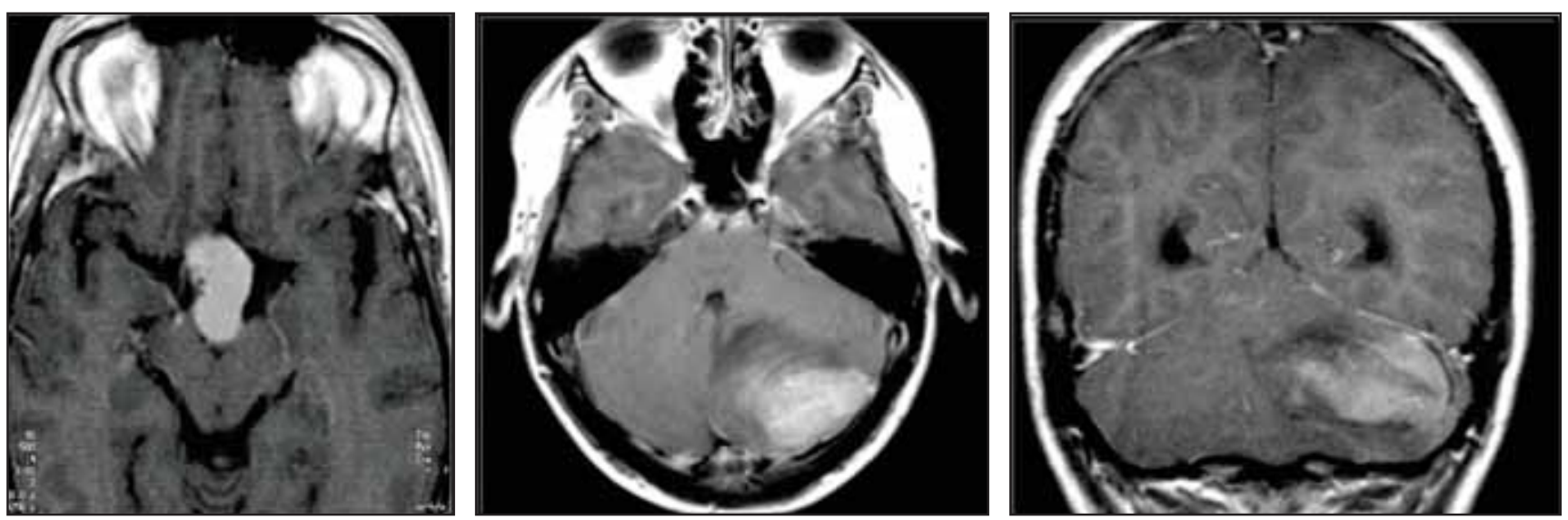

FIGURA 1. Meduloblastom. MRI secțiune axială şi coronală: masă neomogenă ce infiltrează substanța albă la nivelul emisferului cerebelos stâng. (Colecția Secției de Neurologie Pediatrică) 
Principala metodă de diagnostic a MBL este reprezentată de explorarea neuroradiologică. Examenele neuroimagistice, CT cerebral şi IRM cerebral, pot evidenția o leziune rotunjită, de linie mediană, ce captează substanța de contrast, localizată frecvent în vermis cu invadarea ventriculului IV şi existența unei hidrocefalii active (Fig. 1). Investigarea pacientului trebuie să cuprindă şi examen IRM spinal pentru depistarea eventualelor diseminări la acest nivel. De asemenea, explorările neuroimagistice ajută la stadializarea corectă a tumorii cu rol important în stabilirea deciziilor terapeutice adecvate (Tabelul 2).

TABELUL 2. Stadializarea neuroimagistică a meduloblastomului

\begin{tabular}{|l|l|}
\hline T1 & $\begin{array}{l}\text { Tumoră < } 3 \mathrm{~cm} \text { diametrul maximal, limitată la vermis, } \\
\text { tavanul ventriculului IV sau emisferul cerebelos }\end{array}$ \\
\hline T2 & $\begin{array}{l}\text { Tumoră } \geq 3 \mathrm{~cm} \text { diametrul maximal, invadând una din } \\
\text { structurile adiacente sau inf Itrând parțial ventriculul IV }\end{array}$ \\
\hline T3A & $\begin{array}{l}\text { Tumoră } \geq 3 \mathrm{~cm} \text { diametrul maximal cu extensie în } \\
\text { apeductul Sylvius, foramen Magendie sau foramen } \\
\text { Luschka determinând astfel hidrocefalie }\end{array}$ \\
\hline T3B & $\begin{array}{l}\text { Tumoră } \geq 3 \mathrm{~cm} \text { diametrul maximal invadând trunchiul } \\
\text { cerebral }\end{array}$ \\
\hline T4 & $\begin{array}{l}\text { Tumoră } \geq 3 \mathrm{~cm} \text { diametrul maximal extinzându-se prin } \\
\text { apeductul lui Sylvius, implicând mezencefalul sau } \\
\text { ventricului III sau trecând de foramenul lui Magendie }\end{array}$ \\
\hline M0 & Fără metastaze \\
\hline M1 & Celule tumorale evidențiate în lichidul cefalorahidian \\
\hline M2 & Tumoră secundară vizibilă la nivel cerebral \\
\hline M3 & Tumori diseminate la nivel spinal vizibile la IRM \\
\hline M4 & Tumoră secundară în afara sistemului nervos central \\
\hline
\end{tabular}

Deoarece MBL metastazează rar la nivel osos sau a altor organe, nu se recomandă metode suplimentare de diagnostic precum radiografia toracică, echografia abdominală sau scintigrafia în absența simptomatologiei sugestive.

Examenul citologic al lichidului cefalorahidian este util pentru a diagnostica eventualele diseminări microscopice leptomeningeale.

Diagnosticul de certitudine este dat de examenul anatomo-patologic.

Tratamentul este complex cuprinzând intervenția chirurgicală, radioterapia şi chimioterapia postoperatorie, terapia suportivă şi de recuperare.

Tratamentul chirurgical este de primă intenție şi trebuie realizat cât mai precoce după diagnostic. Scopul este rezecția completă a tumorii, decomprimarea fosei posterioare şi ameliorarea hidrocefaliei. Collange şi colaboratorii (2016) consideră că aproximativ 32,45\% dintre pacienții cu MBL necesită shunt pentru drenajul lichidului cefalorahidian după îndepărtarea chirurgicală a tumorii (19). Kombogiorgas (2008) a raportat că 20\% dintre bol- navii cu MBL operați au avut nevoie de shunt pentru drenajul lichidului cefalorahidian (16). De asemenea, Gopalakrishnan (2012) a arătat că 36,8\% din 38 pacienți cu MBL urmăriți au necesitat shunt pentru drenajul lichidului cefalorahidian (20).

Wang (2013) consideră că prognosticul depinde de gradul de rezecție a tumorii (12). Monteight (2006) a studiat 36 de pacienți cu MBL, dintre care 16 au beneficiat de rezecția completă a tumorii, la 14 rezecția a fost incompletă, iar la 6 s-a făcut doar puncție biopsie, observând că toți cei la care s-a putut realiza îndepărtarea chirurgicală completă a MBL au avut o rată de supraviețuire mai mare (21). Intotdeauna postoperator trebuie efectuat examen IRM cerebral de control, într-un interval de timp de 24-72 de ore după intervenția chirurgicală. În ultimii ani mortalitatea raportată după intervențiile chirurgicale de rezecție a MBL se apropie de 0 , dar sechelele neurologice postoperatorii au o incidență crescută de până la $57 \%$, cele mai frecvente fiind reprezentate de ataxie cerebeloasă şi pareza de nervi oculomotori, semne ce se pot ameliora în timp (22).

Radioterapia reprezintă cel mai eficient tratament adjuvant în MBL şi se aplică cerebral şi spinal, fără limitare doar la fosa posterioară, chiar dacă nu au fost identificate însămânțări la distanță. Scopul principal la radioterapiei este de a preveni recurențele locale (19). Dozele folosite sunt de 3540 Gy pentru axul cerebrospinal şi de 55-60 Gy pentru patul tumoral şi pentru eventualele metastaze (23). Rutkowski (2009) consideră că la copiii cu vârstă mai mică de 3 ani radioterapia trebuie evitată (24). Această idee este susținută de rezultatele studiului lui Lafay-Cousin (2009) care, evaluând 29 de copii cu vârsta de 3 ani sau mai mici, diagnosticați cu MBL, a remarcat că la cei care au primit radioterapie s-a înregistrat o scădere semnificativă a coeficientului de inteligență (IQ) şi a performanțelor şcolare comparativ cu cei la care această metodă de tratament a fost temporizată (25). De asemenea, Thakur şi colaboratorii (2016) au observat că din cei 52 de pacienți de vârstă pediatrică diagnosticați cu MBL care au beneficiat numai de radioterapie ca tratament adjuvant, $20 \%$ au prezentat toxicitate hematologică acută care a fost depistată în timpul radioterapiei, dar şi după întreruperea acesteia (26).

Chimioterapia poate fi folosită în tratamentul acestui tip de tumoră, deoarece MBL este în general chimiosensibil. La copiii sub vârsta de 3 ani chimioterapia reprezintă principala terapie adjuvantă deoarece în neuro-oncologia pediatrică utilizarea ei este indicată atât pentru a îmbunătăți supraviețuirea pacienților cât şi pentru a temporiza începerea 
radioterapiei care are numeroase efecte secundare severe pe termen lung la copilul mic. În literatură există diferite protocoale, chimioterapicele cel mai frecvent utilizate fiind lomustina, cisplatin, carboplatin, vincristina şi ciclofosfamida în diferite combinații (27).

Terapia suportivă şi de reabilitare neuromotorie reprezintă componente importante în managementul actual al copiilor cu MBL în încercarea de a ameliora deficitele neuropsihice care sunt frecvente la aceşti pacienți.

\section{PROGNOSTIC}

În anii ' 90 , rata de supraviețire la 10 ani a copiilor cu MBL era 50\%. În prezent, prin tehnici moderne de tratament, 50-60\% dintre pacienții de vârstă pediatrică operați mai prezintă progresie tumorală la 5 ani după diagnostic. Asocierea polichimioterapiei postoperatorii la copiii cu tumori restante a condus la creşterea ratei de supraviețuire la 5 ani până la $80 \%$ (28). Unii autori consideră că parametri precum vârsta, sexul, întinderea leziunii şi varianta histopatologică nu influențează semnificativ rata de supraviețuire (29).

Prognosticul este influențat şi de prezența sechelelor neuropsihice şi endocrine importante care pot fi prezente la aceşti pacienți şi care sunt din cauza efectelor directe şi indirecte ale tumorii, intervenţiei chirurgicale, a radioterapiei şi chimioterapiei. Patel (2015) a urmărit timp de 36-58 luni un grup de 100 copii, cu vârste cuprinse între 3 şi 14 ani, diagnosticați cu MBL, care au beneficiat de tratament chirurgical asociat cu radioterapie şi chimioterapie, raportând prezența defícitelor neurologice la $63 \%$ dintre pacienți şi a problemelor endocrine la 58\% (30). Alte studii au raportat la copiii cu MBL numeroase efecte secundare post-terapeutice precum scăderea IQ, tulburări vizuale, modificări ale comportamentului adaptativ, deficite neuromotorii (28). Maddrey (2005) a evaluat prin teste neuropsihologice 16 copii cu MBL la 10 ani de la diagnostic şi intervenţia terapeutică şi a raportat valori ale IQ cuprinse între 54 şi 110 , media fiind de 75 (31). De asemenea, Philip şi colaboratorii (2016) au observat un declin neurocognitiv la $48 \%$ dintre copiii diagnosticați cu MBL care au beneficiat de tratament chirurgical urmat de radioterapie şi chimioterapie (29).

\section{CONCLUZII}

Meduloblastomul este o tumoră malignă întâlnită frecvent la vârsta pediatrică al cărei tablou clinic este dominat de semne de hipertensiune intracraniană severă şi ataxie cerebeloasă. Explorarea neuroimagistică este esențială în diagnosticarea şi stadializarea tumorii. În prezent tratamentul multimodal a ameliorat mult prognosticul acestor pacienți. Managementul actual al bolii cuprinde şi terapia suportivă şi de reabilitare neuropsihomotorie care contribuie la îmbunătățirea calității vieții acestor copii. 